\title{
Poor control and management of type 2 diabetes mellitus at an under-resourced South African Hospital: is it a case of clinical inertia?
}

\author{
Romona Devi Govender ${ }^{a *}$, Prem Gathiram $^{\mathrm{a}}$ and Miljenko Panajatovic ${ }^{\mathrm{b}}$ \\ ${ }^{a}$ Department of Family Medicine, College of Health Sciences, Nelson R Mandela School of Medicine, University of KwaZulu-Natal, Durban, South \\ Africa

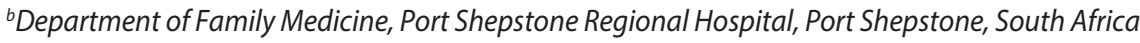 \\ *Corresponding author, email: govenderr@uaeu.ac.ae

Evidence shows that even with the implementation of evidence-based medicine, the attainment of optimal glycaemic control is difficult and challenging for both patients and healthcare providers. This study was a one-year retrospective chart review with data collected during the period October 2010 to December 2010 of patients with Type 2 diabetes mellitus (T2DM) who attended the outpatients' department at the Port Shepstone Regional Hospital (PSRH), South Africa (SA). The total study population was 360 patients with $51 \%$ Black African, $32 \%$ Indian, $16 \%$ White and $1 \%$ Coloured. Of the 111 patients' charts only $78 \mathrm{had}$ two consecutive $\mathrm{HbA} 1 \mathrm{c}$ levels recorded. Of the $78 / 111$ patients, only 10 patients had the target $\mathrm{HbA} 1 \mathrm{c}$ level of $<7 \%$ at visit 1. By visit two, $15.4 \%(n=12)$ had achieved the target HbA1c level. Over the one-year chart review only $3 / 111(2.7 \%)$ maintained their $\mathrm{HbA} 1 \mathrm{c}$ level of $<7 \%$ and 5/111 patients whose treatment was revised according to the 2009 SEMDSA guidelines reached $\mathrm{HbA} 1 \mathrm{c}<7 \%$ by visit 2 whilst $4 / 111$ patients, whose treatment schedule was not modified according to the 2009 SEMDSA guidelines, also reached $\mathrm{HbA1c}<7 \%$ at visit 2 . However, this one-year chart review showed that glycaemia was poorly managed at this hospital, which may be explained by clinical inertia.

Keywords: Type 2 diabetes mellituscontrol and management, clinical inertia, glycated haemoglobin

\section{Introduction}

Diabetes mellitus (DM) is a chronic metabolic disease that is characterised by hyperglycaemia and is becoming one of the main medical challenges worldwide, with more diabetes-related deaths occurring in low- and middle-income countries than in the high-oncome ones. ${ }^{1,2}$ It has been estimated that from 1980 to 2008 the number of people with DM increased from 153 million to 347 million and the age standardised prevalence was slightly higher in men (9.8\%) than women (9.2\%). ${ }^{3}$ The WHO estimated that globally, in 2014, 422 million adults over the age of 18 were living with diabetes. ${ }^{2}$ A recent study has estimated that by 2030 there will be 439 million people living with DM. ${ }^{4}$ In sub-Saharan Africa, it is estimated that the prevalence of DM will be about 18 million by $2030 .{ }^{5}$ However, this estimation excludes the impact of urbanisation, ageing and obesity; and with the United Nations (UN) projecting that, by $2025,54.1 \%$ Africans would be living in urban areas, ${ }^{5}$ the actual prevalence may be higher than that estimated. The impact of age on type 2 DM (T2DM) differs among countries; in high-income countries (as classified by the World Bank) most people with diabetes are aged over 60 years, while for low- and middle-income countries, like South Africa, most people with diabetes are of working age, between 40 and 60 years. ${ }^{4} \mathrm{~A}$ recent study showed the prevalence of T2DM amongst South Africans above 30 years of age to be at around 9\%, with $7.4 \%$ in men and $10.4 \%$ in women. ${ }^{6}$

Blood glucose monitoring is important in optimising long-term outcomes towards reducing the co-morbid conditions that may arise in patients with T2DM. There is strong epidemiological evidence to use glycated haemoglobin $(\mathrm{HbA} 1 \mathrm{c})<7 \%$ as the target level and patients with T2DM with an $\mathrm{HbA} 1 \mathrm{c}$ level of $>7.5 \%$ have a 2.5 to 5 -fold greater relative risk of developing microvascular complications. ${ }^{7}$ The South African ${ }^{7,8}$ as well as other international guidelines ${ }^{9,10}$ for managing T2DM use HbA1c as a primary glycaemia control monitoring tool and to quantify the degree of risks in the development of complications due to DM. ${ }^{11}$ The target level of below $7 \%$ has been recommended by the American Diabetes Association (ADA) of $2012^{10}$ and has been advocated by the SEMDSA guidelines. ${ }^{8}$

Clinical inertia is the failure to set glycaemic targets and to implement and escalate treatment to achieve these set target goals. ${ }^{12}$ Clinical inertia is a global phenomenon and the causes are related to patient and physician factors and factors related to the system in which the physicians work. ${ }^{12}$ Evidence from both developed and developing countries shows that, even with the implementation of evidence-based medicine, the attainment of optimal glycaemia control is difficult and challenging not only for patients but also for their healthcare providers.,13-17 Coupled with these multifactorial reasons for poor glycaemia control and clinical inertia, ${ }^{12}$ South Africa has the added burden of being an under-resourced country, leading to an increase in long-term diabetic complications. Further, the outpatients' department of Port Shepstone Regional Hospital (PSRH), where the study was conducted, had 3908 visits by patients with DM in $2010 .{ }^{18}$ Over a 5-month period in 2011, 312 (21\%) of 1519 patients were admitted to this hospital with complications of DM. ${ }^{18}$ This presents an added challenge for SA where diabetes care must compete for resources with communicable diseases such as HIV/ AIDS and TB.

This study therefore evaluated the monitoring and management of T2DM in an under-resourced hospital in a peri-urban/rural setting in South Africa. To the best of our knowledge, no studies 
of this nature have been recently undertaken in any of our public hospitals in the province of KwaZulu-Natal (KZN). Hence it will be important to know whether patients with T2DM are adequately managed at PSRH in particular and by extension in KZN, which uses the SEMDSA guidelines. ${ }^{8}$

\section{Materials and methods}

\section{Ethical considerations}

Ethical approval for this study was obtained from the Biomedical Research Ethics Committee (BE 122/010) of the University of KwaZulu-Natal and permission to conduct the study at the PSRH was received from the health institution.

\section{Study design}

This study was a one-year retrospective chart review with data collected during the period October 2010 to December 2010 of patients with T2DM who attended the outpatients' department (OPD) at PSRH, South Africa.

\section{Clinical setting}

According to the South African Department of Health, PSRH receives referral of patients from 21 clinics in the Ugu district of KZN. The referrals are based on the needs of the patient that are beyond the scope of practice at the local clinics, namely patients who need a higher level of clinical care. Therefore, patients attending the OPD of PSRH were either referred from the clinics or were patients with diabetes discharged following admission to PSRH.

The following data were extracted from patient charts and captured on the data collection sheet:

(1) demographic and disease profile (age, gender, race, height, weight, BMl, age at diagnosis and duration of treatment for T2DM);

(2) two consecutive $\mathrm{HbA1c}$ levels at two visits irrespective of the date of the consecutive visits (visits1 and 2);

(3) the number of patients who achieved the target $\mathrm{HbA} 1 \mathrm{c}$ level of $7 \%$, and number that had defaulted for follow-up;

(4) patients' treatment outcomes based on $\mathrm{HbA1c}$ value;

(5) blood pressure and hyperlipidaemia management.

\section{Statistical analysis}

The results are stated as means \pm standard deviation (SD). The data were processed and analysed for statistical significance using SPSS version $19.0^{\circledR}$ (SPSS Inc., Chicago, IL, USA). Means and SD were used to summarie continuous variables while frequency tables were used for categorical variables. Differences in means by group were assessed using Student's t-test (for two-group comparison) or one-way analysis of variance (ANOVA) (for three or more group comparison). Pearson's chi-square test was used to assess association between two categorical variables (contingency tables). A $p$-value of $<0.05$ was deemed statistically significant.

\section{Results}

\section{Demographic and disease profile}

From October to December 2010, 360 T2DM patient charts were seen and hence the patient record files of all these patients were retrieved. These patient files (hereinafter referred to as patients only) were of $51 \%$ black South Africans, $32 \%$ Indians, $16 \%$ Whites
Table 1: Distribution of sample by ethnicity, gender, $\mathrm{HbA} 1 \mathrm{c}$ and RBG levels

\begin{tabular}{lccc}
\hline Ethnic group & Total (\%) & Females, $n(\%)$ & Males, $n(\%)$ \\
\hline Black African & $185(51)$ & $136(57)$ & $49(41)$ \\
\hline Indian & $114(32)$ & $73(30)$ & $41(34)$ \\
White & $57(16)$ & $28(12)$ & $29(24)$ \\
Coloured & $4(1)$ & $3(1)$ & $1(1)$ \\
\hline Total sample & $360(100)$ & $240(100)$ & $120(100)$ \\
Monitoring by HbA1c levels & & \\
Black African & $47(40.5 \%)$ & $33(44.6 \%)$ & $14(33.3 \%)$ \\
$\begin{array}{l}\text { Indian } \\
\text { White }\end{array}$ & $52(44.8 \%)$ & $33(44.6 \%)$ & $19(45.2 \%)$ \\
$\begin{array}{l}\text { Coloured } \\
\text { Total }\end{array}$ & $16(13.8 \%)$ & $7(9.4 \%)$ & $9(21.5 \%)$ \\
$\begin{array}{l}\text { Monitoring by RBG } \\
\text { levels }\end{array}$ & $116(100 \%)$ & $74(63.8 \%)$ & $0(0 \%)$ \\
$\begin{array}{l}\text { Female:male (total } \\
\text { sample) }\end{array}$ & $244(100 \%)$ & $166(68 \%)$ & $78(32 \%)$ \\
\hline
\end{tabular}

and $1 \%$ Coloureds (Table 1). The ratio of female to male T2DMs for the total study sample was 2 to 1 (Table 1). Blood glucose levels were monitored using either $\mathrm{HbA} 1 \mathrm{c}(n=111)$ or random blood glucose (RBG) $(n=244)$ methods; 5 charts did not have any data recorded.

The one-year chart review showed that in 111 patients only 78 files recorded 2 consecutive $\mathrm{HbA} 1 \mathrm{c}$ levels and 33 had only 1 $\mathrm{HbA} 1 \mathrm{c}$ level recorded (Figure 1 and Table 3). For this paper, the data for charts with $1 \mathrm{HbA} 1 \mathrm{c}$ level and charts with only RBG as a monitoring tool have been excluded. Of the patients with $\mathrm{HbA} 1 \mathrm{c}$, 44.8\% were Indians, 40.5\% Black South Africans and 13\% White and $0.9 \%$ Coloureds (Table 1). Table 2 shows the age, age at diagnosis, and duration of treatment for female and male patients. Female patients had a significantly higher BMI $(p<$ 0.001 ) compared with males and were obese whilst the males were overweight.

Table 3 shows the mean $\mathrm{HbA} 1 \mathrm{c}$ levels for the 78 patients at visits 1 and 2 . In those males and females who had $\mathrm{HbA} 1 \mathrm{c}<7 \%$, there was no significant difference between visits $1 \& 2$. However, in patients with $\mathrm{HbA} 1 \mathrm{c} \geq 7 \%$, the total level (males and females combined) at visit 2 was significantly less than that at visit $1(p<0.05)$.

Figure 1, a flow diagram, depicts patients who were monitored using $\mathrm{HbA} 1 \mathrm{c}$ for two serial visits (visits 1 and 2) during the oneyear review period. This review showed that only 78/111 patient files showed 2 consecutive $\mathrm{HbA} 1 \mathrm{c}$ levels being recorded whilst in 33 only one $\mathrm{HbA} 1 \mathrm{c}$ and in 5 no levels were recorded (see Figure 1). In only 10/116 (8.6\%) was the target $\mathrm{HbA} 1 \mathrm{c}$ level $<7 \%$ attained at visit 1 . In the majority of these patients $(8 / 10)$ their prescriptions were not revised prior to visit 2 and among the 10 patients only 3 patients maintained the target level by visit 2 with a mean $\mathrm{HbA} 1 \mathrm{c}$ of $6.1 \pm 0.2 \%$. The 68 patients with $\mathrm{HbA} 1 \mathrm{c} \geq 7 \%$ had their prescriptions either revised or not revised following the established guidelines. In 40 patients, revisions were done according to the 2009 SEMDSA guidelines whilst in 28 the guidelines were not followed; i.e. either no revisions were made in 25 or there was a downscaling of prescription in 3 (see Figure 2). Nine of the 68 patients reached the target $\mathrm{HbA} 1 \mathrm{c}$ level of $6.1 \pm 0.5$ ) at visit 2 (see Figure 1). Surprisingly, 3 of the 28 patients in whom the SEMDSA guidelines were not followed 


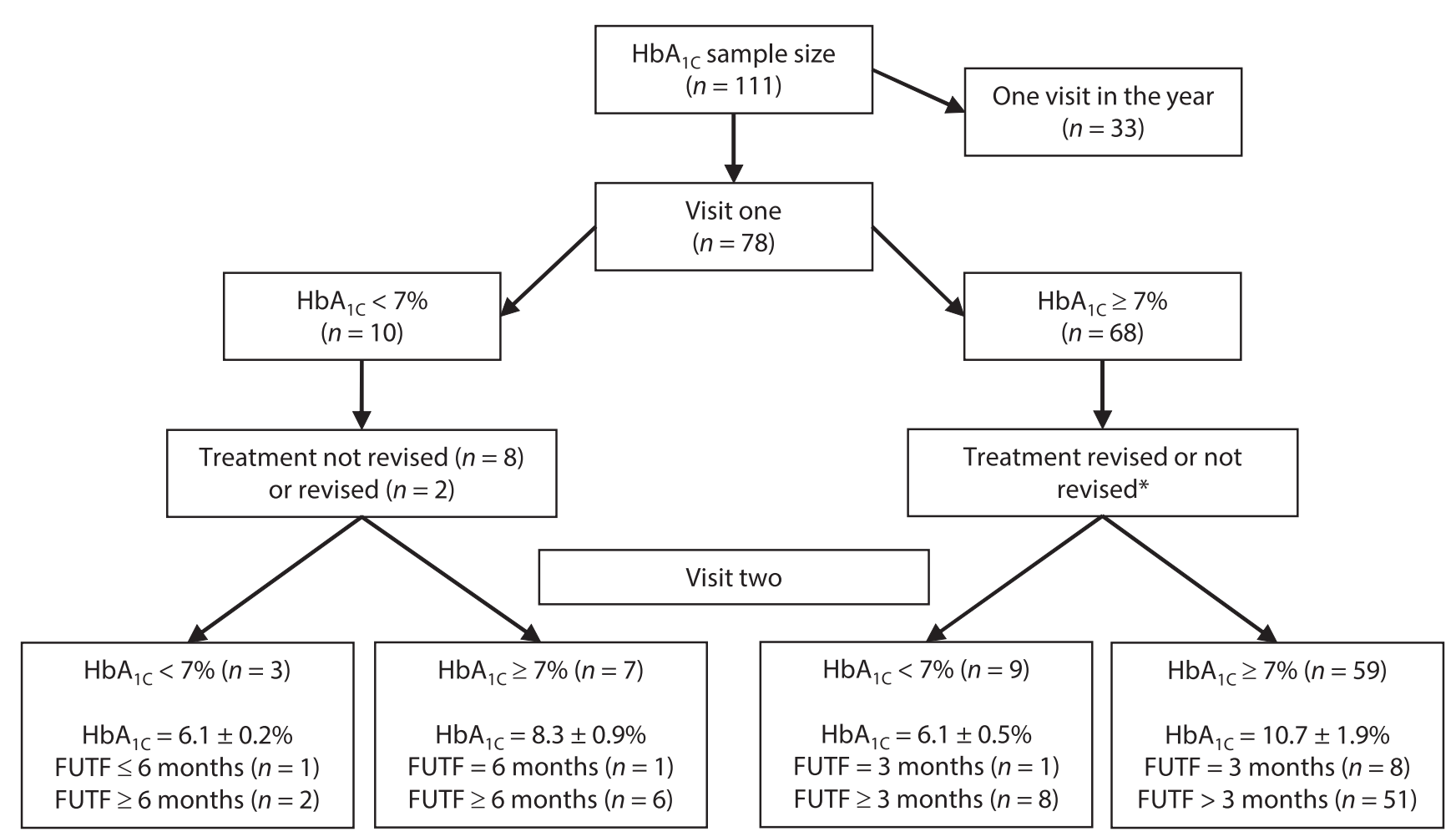

Figure 1: Flow diagram of patients treated and monitored using $\mathrm{HbA} 1 \mathrm{c}$ levels at visits 1 and 2.

*According to SEMDSA 2009 guidelines.

Table 2: Age, age at diagnosis, duration of treatment year and body mass index (BMI) of the 116 patients monitored by glycated haemoglobin $(\mathrm{HbA} 1 \mathrm{c}$ ) levels (all data are mean $\pm \mathrm{SD}$ )

\begin{tabular}{lccc}
\hline Variables & Females $(n=74)$ & Males $(n=42)$ & $p$-value \\
\hline Age (years) & $60( \pm 10)$ & $59( \pm 11)$ & 0.76 \\
$\begin{array}{l}\text { Age (years) at diag- } \\
\text { nosis }\end{array}$ & $50( \pm 11)$ & $50( \pm 10)$ & 0.84 \\
$\begin{array}{l}\text { Duration of treatment } \\
\text { in years }\end{array}$ & $9( \pm 7)$ & $9( \pm 6)$ & 0.88 \\
BMl $\left(\mathrm{kg} / \mathrm{m}^{2}\right)$ & $34( \pm 7)$ & $28( \pm 4)$ & $<0.001$ \\
\hline
\end{tabular}

also reached target $\mathrm{HbA} 1 \mathrm{c}$ value (see Figure 2). The other 59 patients with $\mathrm{HbA} 1 \mathrm{c} \geq 7 \%$ had a mean $\mathrm{HbA} 1$ c level of $10.7 \pm 1.9 \%$. Irrespective of $\mathrm{HbA} 1 \mathrm{c}$ values, 67 patients had a follow-up time frame (FUTF) longer than that stipulated by the 2009 SEMDSA guidelines (see Figure 1). Of those who had $\mathrm{HbA} 1 \mathrm{c}$ levels $<7 \%$ at visit 1, 8 patients had an FUTF of $>6$ months at visit 2, whilst among 59/68 who had $\mathrm{HbA} 1 \mathrm{C} \geq 7 \%$ at visit 1, 51 had an FUTF of $>3$ months at visit 2 . In summary, over the one-year chart review only $3 / 111(2.7 \%)$ patients maintained their $\mathrm{HbA} 1 \mathrm{c}$ level of $<7 \%$.

\section{Treatment outcomes in relation to SEMDSA guidelines recommendations}

Table 3 shows the drop in HbA1c levels between visits 1 and 2 in patients with $\mathrm{HbA} 1 \mathrm{c}$ level above the target range. The patients who maintained $\mathrm{HbA} 1 \mathrm{c}$ within target range $(\mathrm{HbA} 1 \mathrm{c}<7 \%)$ were on regimens such as monotherapy with metformin, or metformin plus insulin. The treatment schedule documented shows that $71.6 \%$ of patients insulin in their regimen (Table 4). No patient was either on diet or diet and exercise alone. This is not in keeping with the SEMDSA guidelines, which advocate the inclusion of metformin with lifestyle modification. The addition of insulin to $\mathrm{OHD}$ is prescribed for patients poorly controlled on OHD only with $\mathrm{HbA} 1 \mathrm{c}$ above the target range (Table 4).

\section{Management of patients with hypertension and co- morbidities}

At the time of analyses of blood pressure and co-morbid conditions of 116 patient files only 82 could be located. Of these all except one were hypertensive (Table 5). Of the 81 only 69 were being treated for the disorder. At visits 1 and 2, the mean systolic blood pressures were about the same, 146.1 \pm 22.4 and $142.5 \pm 22.3 \mathrm{~mm} \mathrm{Hg}$, respectively, while the mean diastolic blood pressures were $82.7 \pm 12.6$ and $80.1 \pm 11.5 \mathrm{mmHg}$, respectively. The systolic blood pressures at visit 1 were controlled in only 23

Table 3: Concentration of $\mathrm{HbA} 1 \mathrm{c}(\%)$ according to gender and total at visits 1 and 2

\begin{tabular}{lcccccc}
\hline \multicolumn{1}{c}{ Visits } & & HbA1c $<7 \%$ & & \multicolumn{2}{c}{ HbA1c $\geq 7 \%$} \\
& Females $(n)$ & Males $(n)$ & Total $(n)$ & Females $(n)$ & Males $(n)$ & Total $(n)$ \\
\hline Visit 1 & $5.9 \pm 0.9(7)$ & $5.6 \pm 0.9(3)$ & $5.8 \pm 0.9(10)$ & $10.6 \pm 2.3(43)$ & $10.5 \pm 2.5(25)$ & $10.6 \pm 2.4(68)$ \\
Visit 2 & $6.0 \pm 0.44(8)$ & $6.4 \pm 0.11(4)$ & $6.1 \pm 0.5(12)$ & $9.8 \pm 2.0(41)$ & $9.5 \pm 1.6(25)$ & $9.7 \pm 1.8(66)$ \\
$p$-values & 0.87 & 0.14 & 0.20 & 0.09 & 0.11 & 78 \\
& & & & & & \\
\hline
\end{tabular}




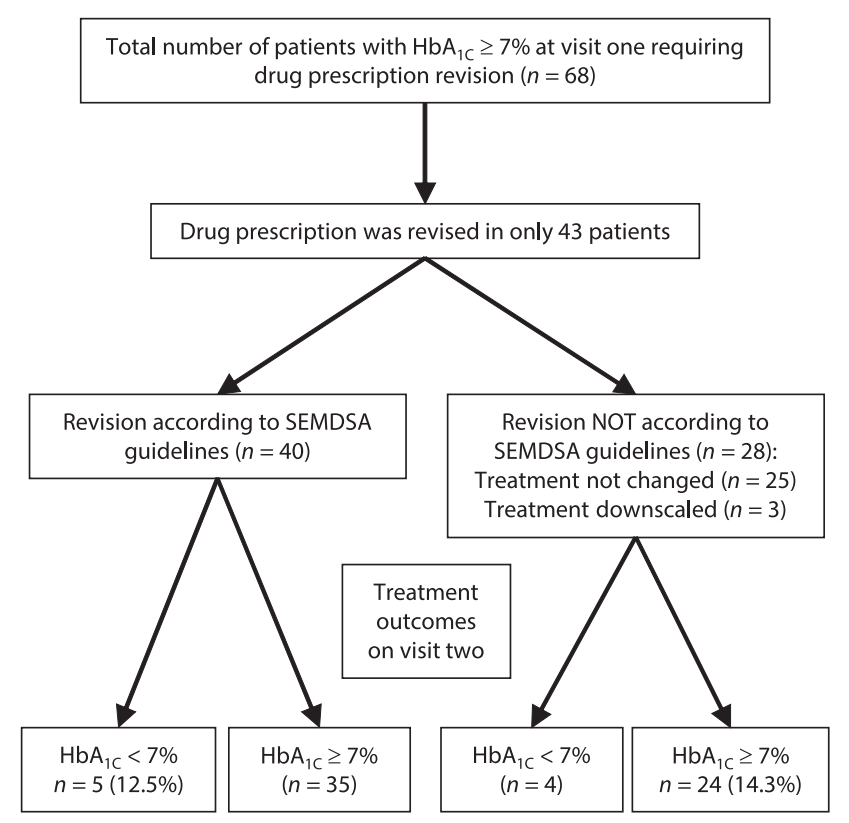

Figure 2: Flow diagram showing patient outcomes following two different prescriptions (according to and not according to 2009 SEMDSA guidelines and not using those prescribed by SEMDSA).

Table 4: Treatment schedules of patients after visit 1

\begin{tabular}{lc}
\hline Treatment schedules & Patients with HbA1c (\%) \\
\hline Diet and exercise & 0 \\
\hline Diet only & 0 \\
OHD monotherapy & 7.7 \\
OHD dual therapy (metformin with & 20.7 \\
sulphonylureas) & 18.1 \\
Insulin alone & 38.8 \\
OHD monotherapy with insulin & 14.7 \\
\hline Dual OHD therapy with insulin & \\
\hline
\end{tabular}

Note: $\mathrm{OHD}=$ oral hypoglycaemic drug.

Table 5: Systolic and diastolic blood pressures, number (\%) of patients with and number treated for hypertension, and number (\%) systolic and diastolic pressures controlled and number (\%) of patients with other comorbid conditions

\begin{tabular}{|c|c|c|}
\hline Parameter & Visit 1 & Visit 2 \\
\hline Systolic BP $(\mathrm{mmHg})$ : mean \pm SD & $146.1 \pm 22.4$ & $142.5 \pm 22.3$ \\
\hline Diastolic BP (mmHg): mean \pm SD & $82.7 \pm 12.6$ & $80.1 \pm 11.5$ \\
\hline $\begin{array}{l}\text { Number (\%) of patients with } \\
\text { hypertension }\end{array}$ & $81(98.8 \%)$ & $81(98.8 \%)$ \\
\hline $\begin{array}{l}\text { Number (\%) of patients treated for } \\
\text { hypertension }\end{array}$ & $69(85.2 \%)$ & 69 (85.2\%) \\
\hline $\begin{array}{l}\text { Systolic pressure: number (\%) } \\
\text { controlled }\end{array}$ & $23(33.3 \%)$ & $28(40.6 \%)$ \\
\hline $\begin{array}{l}\text { Diastolic pressure: number (\%) } \\
\text { controlled }\end{array}$ & $28(40.6 \%$ & $38(55.1 \%)$ \\
\hline Other co-morbid conditions & \multicolumn{2}{|c|}{1 year period, $n(\%)$} \\
\hline Hypercholesterolemia & \multicolumn{2}{|c|}{$36(43.9)$} \\
\hline Hypothyroidism & \multicolumn{2}{|c|}{$11(13.4)$} \\
\hline Ischaemic heart disease & \multicolumn{2}{|c|}{$9(11)$} \\
\hline Glaucoma & \multicolumn{2}{|c|}{$3(3.7)$} \\
\hline Chronic kidney failure & \multicolumn{2}{|c|}{$10(12.2)$} \\
\hline
\end{tabular}

(33.3\%) patients and at visit 2 in $28(40.6 \%)$, whilst the diastolic blood pressure was controlled in $28(40.6 \%)$ and $38(55.1 \%)$ at visits 1 and 2, respectively. The major comorbid conditions treated were hypercholesterolemia ( $n=36$ or $43.9 \%$ ), hypothyroidism ( $n$ $=11$ or $13.4 \%)$, ischaemic heart disease and cerebrovascular accident ( $n=9$ or $11 \%$,) glaucoma ( 3 or $3.7 \%$ ) and chronic kidney failure (10 or $12.2 \%$ ) (Table 5). Of the latter, 7 were treated for grade 3 plus 1 and 2 for grades 4 and 5 chronic kidney disease, respectively. No patients were screened for any of the above conditions but were treated only if they presented with signs and symptoms of any of the diseases mentioned in Table 5.

\section{Discussion}

The Ugu district of KwaZulu-Natal, a Province in South Africa, has a population of 722484 with $82 \%$ being rural. Although this is not a prevalence study, the ethnic profiling in KwaZulu-Natal is $90.9 \%$ Black African, 3.4\% Indian, 4.7\% White and $0.8 \%$ Coloured. ${ }^{19}$ The sample in this study consisted of 51\% Black African, 32\% Indian, $16 \%$ White and $1 \%$ Coloured patients. If we correlate these with the overall percentage ethnic distribution in Ugu, the number of Indian patients is much higher than Black Africans and other racial groups. It is known that the South African Indian population has the highest prevalence of diabetes in this province and nationally. A previous epidemiological study done 20 years ago showed the prevalence in the South African Indian community to be between $12 \%$ and $13 \% .^{20} \mathrm{~A}$ recent study reported the prevalence of DM (age standardised) to be about 20\% amongst Indians living in a suburb near Durban. ${ }^{21}$ Despite a high prevalence amongst Indian patients, the current trend in South Africa is an increase of T2DM in the urban-based, Black South Africans and a much earlier diagnosis, ${ }^{6}$ which is a new phenomenon.

The patient charts reviewed in this study were of patients either referred from the surrounding clinics to the hospital or patients who were discharged following admission to PSRH. This study evaluated the monitoring and management of T2DM using clinical guidelines. The principal benefit of clinical guidelines is to improve the quality of care received by patients..$^{22}$ An international study conducted in 2002 in five European countries showed that $42 \%$ of the total patient population had an $\mathrm{HbA} 1 \mathrm{c}>7.5 \%$ and $37 \%$ had not received an $\mathrm{HbA} 1 \mathrm{c}$ test within a six-month period despite the implementation of guidelines. ${ }^{23}$ In a local study, an intervention using the national guidelines was implemented in 18 public sector community health clinics and the outcome showed no benefit to diabetic care, with poor glycaemia control and $64.1 \%$ of the patients having an $\mathrm{HbA} 1 \mathrm{c}$ level of $\geq 7 \% .{ }^{24}$ The results obtained from our present study suggest poor glycaemia control. The entity of clinical inertia can be used to explain this outcome. Clinical inertia is failure of the physician to initiate or intensify treatment of patients with T2DM whose health may improve as a result of early intensification ${ }^{25}$ or timely follow-up of the patient as per the 2009 SEMSDA $^{8}$ guidelines, which is not evident in the present study. It also means that there is a tendency for the physician to continue with the current treatment despite the blood results ( $\mathrm{HbA} 1 \mathrm{c} \geq 7 \%$ ) suggesting that treatment be escalated. ${ }^{22,26}$ In the present study we found that despite following the 2009 SEMDSA guidelines only 5 patients whose treatment was revised at visit 1 reached the $\mathrm{HbA} 1 \mathrm{c}$ target range on visit 2 , and 4 of the 28 patients whose treatment schedule modification was not done according the 2009 SEMDSA guidelines, i.e. no revisions were made in 25 patients and the prescription was downscaled in 3 patients (not according to the SEMDSA guidelines), also reached $\mathrm{HbA} 1 \mathrm{c}$ target range at visit 2. These two different approaches reached the same outcome and this highlights the complexity associated with managing patients with diabetes. It can also be inferred that, if the $\mathrm{HbA} 1 \mathrm{c}$ 
level of $\geq 7 \%$ suggested treatment be escalated and despite it not being done some patients still achieved the target level of $\mathrm{HbA} 1 \mathrm{c}$ $<7 \%$ this shows the influence of patient factors, such as some behaviour change, may be playing a role. O'Connor et al. noted that advances in behaviour change science support improved diabetes care and reduced clinical inertia. ${ }^{25}$

According to O'Connor et al. (2005) physician factors contribute to $50 \%$ of clinical inertia, with the others being patient factors (30\%) and office factors (20\%). ${ }^{25}$ Patients themselves contribute to clinical inertia as they are ill equipped in medication knowledge, and lack adherence to lifestyle changes and medication and self-management practices. ${ }^{27,28}$ Perhaps this may have contributed to the 35 of the 40 patients whose treatment, despite being revised according to the SEMDSA guidelines, had an $\mathrm{HbA} 1 \mathrm{c}$ level of $\geq 7 \%$ at visit 2 . South Africa has a burden of patient load which, coupled with a shortage and misdistribution of physicians, worsens the situation..$^{26,27}$ This adds further to the clinical inertia related to patient management.

In this study, the participants were mainly a rural or peri-urban population, of low socio-economic status and with a limited level of formal education; self-monitoring and self-management will therefore be a challenge (personal observation) and compliance with treatment (including diet, physical activity and medication) could also be questionable. Office factors include dispensation of clinical guidelines to all physicians attending to patients with diabetes and the availability of investigations to objectively assess glycaemia control immediately for therapeutic review. In a study conducted in remote Australia looking at 'point-of-care' testing for $\mathrm{DM}$, i.e. the $\mathrm{HbA} 1 \mathrm{c}$, this is done on site and the result was obtained in 6 min. ${ }^{29}$ The adoption of a similar system in South Africa may alleviate the challenges related to delayed turn-around laboratory times related to $\mathrm{HbA} 1 \mathrm{c}$ testing and may improve glycaemia control, treatment and patient outcomes. In addition, the PSRH does not have a dedicated clinic day to see only patients with diabetes; rather, all patients are seen in its outpatients department, irrespective of the clinical problem. Furthermore, to compound the problem, the hospital itself does not accept patients that were not referred to it but rather when the peripheral clinics decide, based on the RBG, to refer the patient to the hospital. Although this study did not assess patient and office factors, these certainly impacted on the clinical outcomes. The following outlines this: at least $50 \%$ of the patients whose charts had HbA1c levels documented were on insulin therapy. Patients, particularly in rural South Africa, do not have the technical support for the use of insulin and the complication of hypoglycaemia. Generally rural patients have a low level of literacy and therefore the use of a daily diary for selfmonitoring, as well as the inability for patients to purchase their own glucometers and to refrigerate the insulin vials are all huge challenges. The results in a recent study of patients younger than 15 years, with T1DM, living in a rural, low-resourced setting in South Africa, showed that they were not supported by family with their diabetes control ${ }^{30}$ while another study showed that $51.4 \%$ were poorly controlled with $\mathrm{HbA} 1 \mathrm{c}$ levels above $10 \% .^{31}$ These are real challenges for both health care professionals and patients alike in South Africa. Therefore the phenomenon of clinical inertia as depicted by the results in this study, where patients with diabetes are not optimally managed, highlights the need for innovative ways to educate patients, provide technical support and develop physician confidence to escalate diabetic management.

In keeping with the poor glycaemia control observed in this study, hypertension was also poorly controlled. Eighty-one of 82 patient files revealed that all except one had hypertension
(98.8\%) and of these 69 (85.2\%) were being treated for the condition. Surprisingly, 12 hypertensive patients were not receiving any treatment. According to the 2009 SEMDSA guidelines the goal should be to maintain a systolic pressure $<130 \mathrm{mmHg}$ and a diastolic pressure $<80 \mathrm{mmHg} .{ }^{8}$ However, in the present study we found the systolic blood pressure was controlled in less than $41 \%$ of hypertensive patients. This also highlights clinical inertia related to co-morbid conditions that contribute to complications and life-threatening outcomes. Other co-morbid conditions that were treated were hypercholesterolemia, hypothyroidism, ischaemic heart disease, cerebrovascular accident and chronic renal failure. Unfortunately, these patients with diabetes were not screened for hyperlipidaemia and other related conditions that may increase the risk of complications. Once again the 2009 SEMDSA guidelines, which state that the total cholesterol should not exceed $4.5 \mathrm{mmol} / \mathrm{l}$ and triglycerides be $<1.7 \mathrm{mmol} / \mathrm{l}$, were not adhered to. ${ }^{8}$ A study conducted at three academic hospital diabetic clinics in Gauteng (one of the provinces in South Africa) also reported suboptimal management of T2DM with only $30 \%$ of the sample having a $\mathrm{HbA} 1 \mathrm{c}<7 \%$, and more than $37 \%$ being obese. $^{32}$

Death due to DM was ranked 5 on the list of the 10 leading causes of death in 2011, representing 4.4\% of all deaths in South Africa and it ranked 3 out of 10 or $5.2 \%$ of all deaths in KZN. ${ }^{33}$ In comparison, in 2001, death due to DM was ranked 7 on the list of 10 leading causes of deaths in South Africa. ${ }^{34}$ This shows that mortality due to DM has increased over the last 10 years. Early diagnosis and effective management of T2DM and other comorbid conditions is more necessary now than ever before in order to change patient outcomes and reduce morbidity and mortality. This will ultimately reduce the increased economic burden to South Africa's health budget.

Although 244 charts were excluded because RBG was used as a monitoring tool, the rationale for random glucose levels at this hospital and perhaps at other state hospitals in South Africa is that patients are not required to fast on the day of their hospital appointment. The challenges related to $\mathrm{HbA1c}$ measurement is that patients have to come back to the hospital after a fortnight for their results. RBG is cost effective and patients do not have to come back a fortnight later to collect their results. More importantly patients' blood glucose is monitored at clinics that are not equipped to do $\mathrm{HbA} 1 \mathrm{c}$ and fasting blood glucose testing is not feasible because they have to travel long distances to the clinic or hospital. These are further barriers affecting good clinical and patient care. Therefore we recommend that all regional hospitals in South Africa should have a dedicated day in the week set aside for a diabetic clinic and this clinic should be responsible for making the necessary patient appointments to avoid this function being undertaken by local clinics, which should only be dispensing medications to T2DM patients. This approach will identify early poor glycaemia control and help reduce morbidity and mortality due to T2DM. We recommend further studies be conducted at this and other regional and district hospitals in the province and perhaps in South Africa as a whole, to gauge the real situation addressing physician, patient, clinic staff and office barrier,s as well as more local best practice for blood glucose monitoring and control.

\section{Limitations}

Limitations of this study include the fact that the target population was peri-urban and rural based and that limited information was recorded in the patient charts with missing 
information, and a number of files were missing from where these are general kept. Although this study provided insight into T2DM management the results need to be interpreted with caution and cannot be axiomatically generalised. A large proportion of the study population $(n=244)$ was excluded for using RBG as a monitoring tool; should this be included, it may result in different study outcomes.

\section{Conclusion}

This audit shows that T2DM is poorly managed at the PSRH and perhaps at other state hospitals in the province. We propose that the poor control and management is perhaps due to clinical inertia. Despite medical treatment being issued by the state, however, test strips for glucometers are not on national tender. Therefore providing test strips will depend on the availability of the budget of each individual public healthcare facility. Although there are diabetes educators and dietitians, they are not routinely available. ${ }^{31}$

Acknowledgements - The authors wish to thank the statisticians for their assistance and the Management of PSRH for allowing them to review patients' record charts.

Conflict of interest - No conflict of interest was reported by the authors.

Notes - All three authors contributed equally to this work.

\section{References}

1. International Diabetes Federation. IDF diabetes atlas. 6th ed. Brussels: Belgium; 2013.

2. World Health Organization. Global report on diabetes. 2016 [cited 2017 March 02]; Available from: http://apps.who.int/iris/ bitstream/10665/204871/1/9789241565257_eng.pdf?ua=1

3. Danaei G, Finucane MM, Lu Y, et al. National, regional, and global trends in fasting plasma glucose and diabetes prevalence since 1980: systematic analysis of health examination surveys and epidemiological studies with 370 country-years and 2.7 million participants. Lancet. 2011 Jul 2;378(9785):31-40. https://doi.org/10.1016/S0140-6736(11)60679-X

4. Shaw JE, Sicree RA, Zimmet PZ. Global estimates of the prevalence of diabetesfor2010and2030.DiabetesRes ClinPract.2010 Jan;87(1):4-14. https://doi.org/10.1016/j.diabres.2009.10.007

5. International Diabetes Federation tE. IDF diabetes atlas, 6th ed. 2013 [cited 10 October 2014]; [1-160]. Available from: http://www.idf.org/ sites/default/files/EN_6E_Atlas_Full_0.pdf

6. Bertram MY, Jaswal AV, Van Wyk VP, et al. The non-fatal disease burden caused by type 2 diabetes in South Africa, 2009. Glob Health Action. 2013;6:19244. https://doi.org/10.3402/gha.v6i0.19244

7. Editorial Office. The 2012 SEMDSA guideline for the management of type 2 diabetes (Revised). JEMDSA. 2012;17(2 Supplement 1):S1-S95.

8. Society for Endocrinology Metabolism and Diabetes of South Africa. SEMDSA guidelines for diagnosis and management of type 2 diabetes mellitus for primary health care-2009. JEMDSA. 2009;14(1):55-8

9. International Diabetes Federation. Global guideline for type 2 diabets. 2012 [cited 2014 October 15]; Available from: http://www. idf.org/global-guideline-type-2-diabetes-2012

10. American Diabetes Association. Diagnosis and classification of diabetes mellitus. Diabetes Care. 2012 Jan;35(Suppl 1):S64-71.

11. American Diabetic Association. Standards of medical care in diabetes-2014. Diabetes Care. 2014 Jan;37(Suppl 1):S14-80.

12. Strain WD, Blüher M, Paldánius $P$. Clinical inertia in individualising care for diabetes: Is there time to do more in type 2 diabetes? Diabetes Ther. 2014;5(2):347-54. https://doi.org/10.1007/s13300-014-0077-8

13. Erasmus RT, Blanco $E$, Okesina $A B$, et al. Assessment of glycaemic control in stable type 2 black South African diabetics attending a peri-urban clinic. Postgrad Med J. 1999 Oct;75(888):603-6. https://doi.org/10.1136/pgmj.75.888.603

14. Blumenthal KJ, Larkin ME, Winning G, et al. Changes in glycemic control from 1996 to 2006 among adults with type 2 diabetes: a longitudinal cohort study. BMC Health Serv Res. 2010;10:977. https://doi.org/10.1186/1472-6963-10-158

15. Kahlon AS, Pathak R. Patterns of glycemic control using glycosylated hemoglobin in diabetics. J Pharm Bioallied Sci. 2011 Jul;3(3):324-8.

16. Zhang SL, Chen ZC, Yan L, et al. Determinants for inadequate glycaemic control in Chinese patients with mild-to-moderate type 2 diabetes on oral antidiabetic drugs alone. Chin Med J (Engl). 2011 Aug;124(16):2461-8.

17. Nam S, Chesla C, Stotts NA, et al. Barriers to diabetes management: patientand providerfactors. Diabetes Res Clin Pract. 2011 Jul;93(1):1-9. https://doi.org/10.1016/j.diabres.2011.02.002

18. Port Shepstone Regional Hospital. Health information report: Port shepstone regional hospital; 2013 May. Report No.: 94, Monthly Health Information Booklet, Port Shepstone: Port Shepstone Regional Hospital.

19. Statistics South Africa. Census 2011 municipal report - KwaZulu-Natal. 2012 [cited 2014 August 26]; Available from: http://www.statssa.gov. za/Census2011/Products/KZN_Municipal_Report.pdf

20. Omar MA, Seedat MA, Dyer RB, et al. South African Indians show a high prevalence of NIDDM and bimodality in plasma glucose distribution patterns. Diabetes Care. 1994 Jan;17(1):70-3. https://doi.org/10.2337/diacare.17.1.70

21. Prakaschandra DR, Esterhuizen TM, Motala AA, et al. High prevalence of cardiovascular risk factors in Durban South African Indians: The Phoenix Lifestyle Project. S Afr Med J. 2016;106(3):284-9. https://doi.org/10.7196/SAMJ.2016.v106i3.9837

22. Larme AC, Pugh JA. Evidence-based guidelines meet the real world: The case of diabetes care. Diabetes Care. 2001 Oct;24(10):1728-33. https://doi.org/10.2337/diacare.24.10.1728

23. Liebl A, Mata M, Eschwège E. Evaluation of risk factors for development of complications in Type II diabetes in Europe. Diabetologia. 2002 Jul;45(S1):S23-S28. https://doi.org/10.1007/s00125-002-0863-0

24. Steyn K, Lombard C, Gwebushe N, et al. Implementation of national guidelines, incorporated within structured diabetes and hypertension records at primary level care in Cape Town, South Africa: a randomised controlled trial. Glob Health Action. 2013;6: 20796. https://doi.org/10.3402/gha.v6i0.20796

25. O'Connor PJ, Sperl-Hillen JAM, Johnson PE, et al. Clinical inertia and outpatient medical errors. In: Henriksen K, Battles JB, Marks ES, Lewin DI, editors. Advances in Patient Safety: From Research to Implementation (Volume 2: Concepts and Methodology). Rockville (MD); 2005;293-308.

26. Weinberger M, Cohen SJ, Mazzuca SA. The role of physicians' knowledge and attitudes in effective diabetes management. Soc Sci Med. 1984;19(9):965-9. https://doi.org/10.1016/02779536(84)90326-5

27. Freeman JS. The increasing epidemiology of diabetes and review of current treatment algorithms. J Am Osteopath Assoc. 2010 Jul;110(7 Suppl):eS2-6.

28. Blumer I. Rethinking diabetes care in Canada. CMAJ. 2004 Nov 23;171(11):1323-4. https://doi.org/10.1503/cmaj.1040796

29. Spaeth BA, Shephard MD, Schatz S. Point-of-care testing for haemoglobin $A 1 \mathrm{c}$ in remote Australian Indigenous communities improves timeliness of diabetes care. Rural Remote Health. 2014 OctDec;14(4):2849.

30. De Villiers FP. The poor children of the poor: Coping with diabetes control in a resource-poor setting. S Afr Med J. 2015 May;105(5):397-9. https://doi.org/10.7196/SAMJ.8496

31. Kalweit KL, Briers N, Olorunju S. The success of various management techniques used in South African children with type 1 diabetes mellitus. S Afr Med J. 2015 May;105(5):400-4. https://doi.org/10.7196/SAMJ.9334

32. Klisiewicz AM, Raal F. Sub-optimal management of type 2 Diabetes Mellitus-A Local Audit. JEMDSA. 2009;14(1):13-6.

33. Statistics South Africa. Mortality and causes of death in South Africa, 2012: Findings from death notifications. 2014; Available from: http:// beta2.statssa.gov.za/?p=3169

34. Statistics South Africa. Mortality and causes of death in South Africa, 1997-2003: Findings from death notification. Pretoria: Statistics South Africa; 2005. Report No. P0309.3. 